\title{
The Madagascar hissing cockroach as a novel surrogate host for Burkholderia pseudomallei, B. mallei and B. thailandensis
}

\author{
Nathan A Fisher ${ }^{1}$, Wilson J Ribot ${ }^{2}$, Willard Applefeld ${ }^{2,3}$ and David DeShazer ${ }^{2 *}$
}

\begin{abstract}
Background: Burkholderia pseudomallei and Burkholderia mallei are gram-negative pathogens responsible for the diseases melioidosis and glanders, respectively. Both species cause disease in humans and animals and have been designated as category B select agents by the Centers for Disease Control and Prevention (CDC). Burkholderia thailandensis is a closely related bacterium that is generally considered avirulent for humans. While it can cause disease in rodents, the $B$. thailandensis $50 \%$ lethal dose $\left(L_{50}\right)$ is typically $\geq 10^{4}$-fold higher than the $B$. pseudomallei and $B$. mallei $\mathrm{LD}_{50}$ in mammalian models of infection. Here we describe an alternative to mammalian hosts in the study of virulence and host-pathogen interactions of these Burkholderia species.

Results: Madagascar hissing cockroaches (MH cockroaches) possess a number of qualities that make them desirable for use as a surrogate host, including ease of breeding, ease of handling, a competent innate immune system, and the ability to survive at $37^{\circ} \mathrm{C}$. MH cockroaches were highly susceptible to infection with B. pseudomallei, $B$. mallei and $B$. thailandensis and the $\mathrm{LD}_{50}$ was $<10$ colony-forming units (cfu) for all three species. In comparison, the $\mathrm{LD}_{50}$ for Escherichia coli in $\mathrm{MH}$ cockroaches was $>10^{5} \mathrm{cfu}$. B. pseudomallei, B. mallei, and B. thailandensis cluster 1 type VI secretion system (T6SS-1) mutants were all attenuated in MH cockroaches, which is consistent with previous virulence studies conducted in rodents. B. pseudomallei mutants deficient in the other five T6SS gene clusters, T6SS-2 through T6SS-6, were virulent in both MH cockroaches and hamsters. Hemocytes obtained from MH cockroaches infected with B. pseudomallei harbored numerous intracellular bacteria, suggesting that this facultative intracellular pathogen can survive and replicate inside of $\mathrm{MH}$ cockroach phagocytic cells. The hemolymph extracted from these MH cockroaches also contained multinuclear giant cells (MNGCs) with intracellular B. pseudomallei, which indicates that infected hemocytes can fuse while flowing through the insect's open circulatory system in vivo.

Conclusions: The results demonstrate that $\mathrm{MH}$ cockroaches are an attractive alternative to mammals to study host-pathogen interactions and may allow the identification of new Burkholderia virulence determinants. The importance of T6SS-1 as a virulence factor in MH cockroaches and rodents suggests that the primary role of this secretion system is to target evasion of the innate immune system.
\end{abstract}

Keywords: Pathogenesis, Melioidosis, Glanders, Virulence, Surrogate host, Type VI secretion system

\footnotetext{
* Correspondence: david.deshazer@us.army.mil

${ }^{2}$ Bacteriology Division, United States Army Medical Research Institute of Infectious Diseases, 1425 Porter St., Fort Detrick, Frederick, MD (301) 21702-5011, USA

Full list of author information is available at the end of the article
} 


\section{Background}

Burkholderia mallei is an obligate parasite of horses, mules and donkeys and no other natural reservoir is known [1]. The organism is a nonmotile gram-negative bacillus that is closely related to Burkholderia pseudomallei and Burkholderia thailandensis. B. pseudomallei is a pathogenic microbe that causes the glanders-like disease melioidosis [2] and B. thailandensis is a weakly pathogenic soil saprophyte [3]. While a handful of Burkholderia virulence determinants have been identified using rodent models of infection [4], research on the molecular mechanism(s) of pathogenesis is still a fertile area. B. mallei, B. pseudomallei, and $B$. thailandensis are able to survive and replicate inside phagocytic cells in a process that involves escape from the endocytic vacuole, replication in the cytosol, intra- and intercellular spread by actin polymerization, and fusion with uninfected cells to form multinucleated giant cells (MNGCs) [4]. Gram-negative pathogens often use secretion systems to deliver virulence factors to the cytosol of host cells, where they modulate cell physiology to favor the microbe. The exploitation of host phagocytic cells by $B$. pseudomallei involves two type III secretion systems (T3SS-1 \& T3SS-3) [5-7], a type V secretion system (BimA) [8], and the cluster 1 type VI secretion system (T6SS-1) [9]. T6SS-1, occasionally referred to as tss-5 [10], is also important for host cell interactions and virulence in B. mallei and B. thailandensis [11,12].

Small mammal models of infection have long been employed to characterize virulence factors of bacterial pathogens, but over the last decade there has been an increase in the use of surrogate hosts to study the pathogenic mechanisms of bacteria $[13,14]$. Several surrogate hosts have been used as alternatives to mammals to study virulence factors and host-pathogen interactions with B. pseudomallei, B. mallei, and B. thailandensis, including Galleria mellonella larvae (wax worms) [15,16], Dictyostelium discoideum (phagocytic amoeba) [17], Caenorhabditis elegans (soil nematode) [18-20], and Solanum lycopersicum (tomato plantlets) [21]. These alternative hosts have allowed the identification of new Burkholderia virulence determinants and have confirmed the importance of virulence factors previously characterized using rodent models of infection.

Insects are popular alternatives to mammalian hosts in large-scale screening studies, owing largely to the high degree of similarity between the innate immune systems of insects and mammals [22]. In both, the recognition of pathogen-associated molecular patterns (PAMPs) by Toll receptors (insects) and Toll-like receptors (mammals) results in the production of antimicrobial peptides [23]. Furthermore, insect hemocytes and mammalian neutrophils can both engulf and kill most invading microorganisms [24]. Insects are also afforded protection from microorganisms through the coagulation and melanization of hemolymph, but they do not have an adaptive immune system.

In addition to biological similarities, several logistical issues contribute to the recent adoption of insects as alternative hosts for bacterial pathogens. Insects can be readily obtained, housed, and cared for at considerable cost savings compared to mammals. Moreover, the use of insects is not governed by animal use regulations or committees and even very large-scale experiments using insects are considered ethically acceptable. As a possible insect alternative to mammalian models of infection, we tested several B. pseudomallei, B. mallei, and $B$. thailandensis strains against juvenile Madagascar hissing cockroaches (MH cockroaches) obtained from a commercial vendor (Carolina Biological Supply Company). MH cockroaches are readily available, easily cultured, and reproduce rapidly. They are larger than wax moth larvae, slow moving compared to other species of cockroaches, and have a substantive carapace. These characteristics make them easier to manipulate and inoculate with known numbers of bacteria compared with other species of insects commonly used for similar studies. $\mathrm{MH}$ cockroaches thrive at $37^{\circ} \mathrm{C}$, a characteristic that is essential for the analysis of mammalian pathogens.

In this study, we found the MH cockroach to be a suitable surrogate host for B. pseudomallei, B. mallei, and B. thailandensis. Burkholderia type VI secretion system mutants were attenuated in $\mathrm{MH}$ cockroaches, which is consistent with what is seen in rodent models of infection $[9,25]$. B. pseudomallei multiplied inside $\mathrm{MH}$ cockroach hemocytes and may be the primary mechanism by which this pathogen avoids elimination by the $\mathrm{MH}$ cockroach innate immune system. The results suggest that $\mathrm{MH}$ cockroaches are a good alternative to mammals for the study of Burkholderia species and possibly other mammalian pathogens.

\section{Results and discussion}

\section{$B$. pseudomallei is virulent in the $\mathrm{MH}$ cockroach and} T6SS-1 mutants exhibit attenuated virulence

In an attempt to determine if the $\mathrm{MH}$ cockroach might serve as a surrogate host for B. pseudomallei, we challenged juvenile MH cockroaches (Figure 1) with K96243 and T6SS mutant derivatives. T6SS-1 is a critical virulence determinant for B. pseudomallei in the hamster model of infection [9], while T6SS-2, T6SS-3, T6SS-4, T6SS-5, and T6SS- 6 are dispensable for virulence in hamsters. Groups of eight $\mathrm{MH}$ cockroaches were challenged by the intraabdominal route with $10^{1}-10^{5}$ bacteria and deaths were recorded for 5 days at $37^{\circ} \mathrm{C}$ (Figure 2).

Figure 2A shows that only one $\mathrm{MH}$ cockroach survived for 5 days after challenge with $10^{1} \mathrm{~B}$. pseudomallei K96243 (Bp), demonstrating that the 50\% lethal dose 


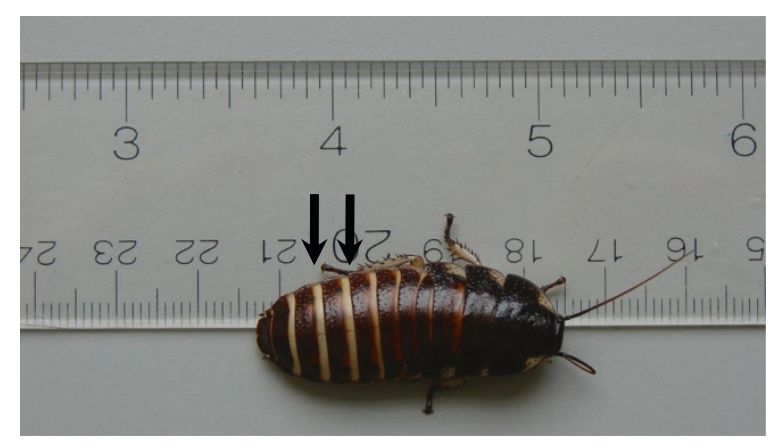

Figure $1 \mathrm{~A}$ representative juvenile Madagascar hissing cockroach used as a surrogate host for B. pseudomallei, $B$. mallei, and $B$. thailandensis infection studies. The black arrows show the locations where bacteria were inoculated into the dorsal abdominal section of the $\mathrm{MH}$ cockroach, between the third and the fifth terga from the posterior.
$\left(\mathrm{LD}_{50}\right)$ is $<10$ bacteria. Similarly, the $\mathrm{LD}_{50}$ for K96243 in the hamster model of infection was $<10$ bacteria [9]. $B$. pseudomallei $\Delta$ hcp 1 is a derivative of $\mathrm{K} 96243$ that lacks the essential tail tube component of the T6SS-1 structural apparatus (Hcp1) and is highly attenuated in the hamster $[9,26]$. B. pseudomallei $\Delta$ hcp 1 was also attenuated in the $\mathrm{MH}$ cockroach (Figure $2 \mathrm{~A}-\mathrm{E}$ ) and the $\mathrm{LD}_{50}$ was $\sim 2 \times 10^{2}$ bacteria on day 5 , which was $>20$ times higher than the $\mathrm{K} 96243 \mathrm{LD}_{50}$ (Table 1). In addition, a dose response was readily apparent with this strain. As the challenge dose increased from $10^{1}$ to $10^{5}$ bacteria, the number and rate of $\mathrm{MH}$ cockroach deaths increased accordingly (Figure 2A-E). It took a challenge dose of $10^{4} \Delta h c p 1$ to kill all eight $\mathrm{MH}$ cockroaches, whereas the minimum lethal dose for K96243 was only $10^{2}$ bacteria (Figure 2). The results demonstrate that $B$. pseudomallei is highly virulent in $\mathrm{MH}$ cockroaches and that T6SS-1 is a critical virulence factor in this insect host. Furthermore, there is a clear correlation between the virulence
A

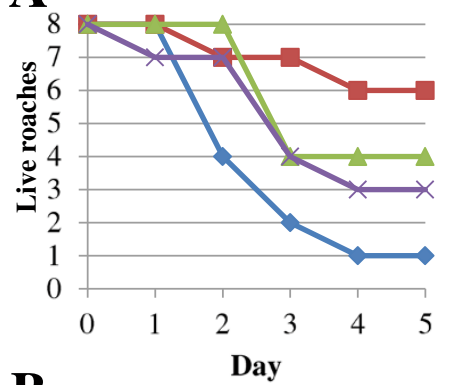

B

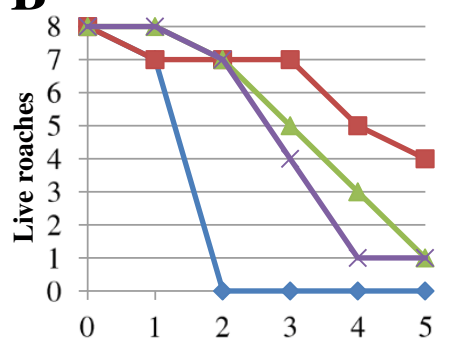

C

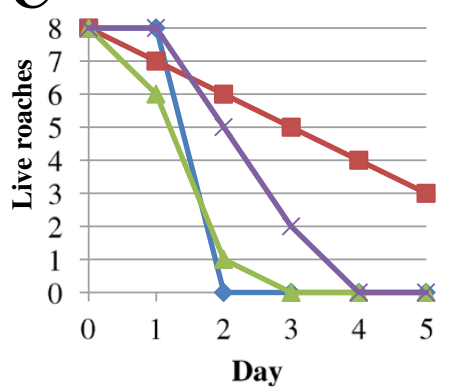

D

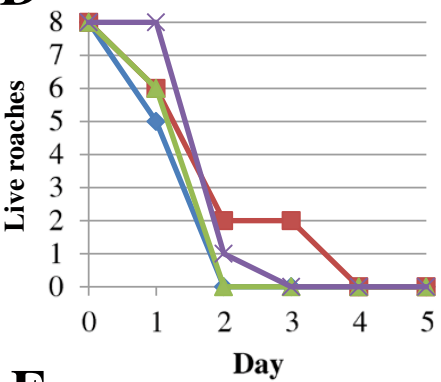

E

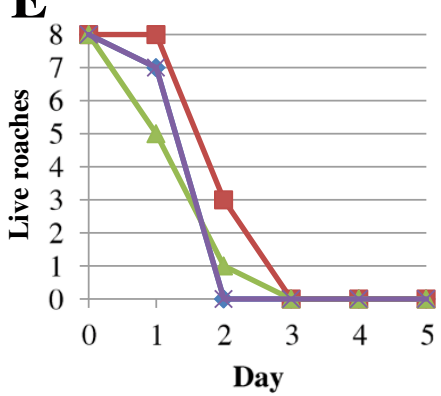

$\multimap \mathrm{BP}$

- $\mathrm{BP} \Delta h c p l$

$\longrightarrow$ BP $\Delta \operatorname{vgrG1-5}$

$\leftarrow$ BP $\Delta \operatorname{vgrG1-3}$,

Figure 2 B. pseudomallei is virulent for the MH cockroach and T6SS-1 mutants are attenuated. Groups of eight MH cockroaches were challenged by the intra-abdominal route of infection and $\mathrm{MH}$ cockroach deaths were monitored for 5 days at $37^{\circ} \mathrm{C}$. (A) $10^{1} \mathrm{cfu}$. (B) $10^{2} \mathrm{cfu}$. (C) $10^{3}$ cfu. (D) $10^{4}$ cfu. (E) $10^{5}$ cfu. Bp, K96243; Bp $\Delta$ hcp1, DDS1498A; Bp $\Delta v g r G 1-5$ ', DDS1503-1A; Bp $\Delta v g r G 1-3$ ', DDS1503-2A. 


\begin{tabular}{|c|c|c|}
\hline Bacterial strain & $\begin{array}{c}\text { Syrian } \\
\text { hamster } \\
\text { LD } \\
50\end{array}$ & $\begin{array}{c}\text { Madagascar } \\
\text { hissing } \\
\text { cockroach } \text { LD }_{50}\end{array}$ \\
\hline \multicolumn{3}{|l|}{ E. coli } \\
\hline MC4100 & $N D^{b}$ & $>10^{5}$ \\
\hline$B / r$ & ND & $>10^{5}$ \\
\hline \multicolumn{3}{|l|}{ B. pseudomallei } \\
\hline K96243 & $<10$ & $<10$ \\
\hline DDS1498A ( $\Delta h c p 1)$ & $>1000$ & 207 \\
\hline DDS0518A ( $\Delta$ hсp2) & $<10$ & $<10$ \\
\hline DDS2098A ( $\Delta h c p 3)$ & $<10$ & $<10$ \\
\hline DDS0171A ( $\Delta h c p 4)$ & $<10$ & $<10$ \\
\hline DDS0099A ( $\Delta h c p 5)$ & $<10$ & $<10$ \\
\hline DDL3105A ( $\Delta$ hcp6) & $<10$ & $<10$ \\
\hline DDS1503-1A ( $\Delta v g r G 1-5)$ & 102 & $<10$ \\
\hline DDS1503-2A ( $\Delta v$ vgrG1-3) & $>450$ & $<10$ \\
\hline $1026 b$ & $<10$ & $<10$ \\
\hline MSHR305 & ND & $<10$ \\
\hline \multicolumn{3}{|l|}{ B. mallei } \\
\hline SR1 & $<10$ & $<10$ \\
\hline DDA0742 ( $\Delta$ hсp 1) & $>10^{3}$ & $>10^{3}$ \\
\hline \multicolumn{3}{|l|}{ B. thailandensis } \\
\hline DW503 & ND & $<10$ \\
\hline DDII0868 ( $\Delta h c p 1)$ & ND & $>10^{3}$ \\
\hline
\end{tabular}

${ }^{\mathrm{a}} \mathrm{LD} \mathrm{D}_{50}, 50 \%$ lethal dose $[9,25,33] ;{ }^{\mathrm{b}} \mathrm{ND}$, not determined.

capacity of B. pseudomallei in the $\mathrm{MH}$ cockroach and the hamster (Table 1).

B. pseudomallei $\Delta v g r G 1-5{ }^{\prime}$ and $\Delta v g r G 1-3^{\prime}$ are K96243 derivatives that have deletions within the gene encoding the tail spike protein (VgrG1) of the T6SS-1 structural apparatus $[9,26]$. These mutants were more virulent than B. pseudomallei $\Delta h c p 1$ in the hamster model of infection [9], but were less virulent than K96243 (Table 1). There was no difference in the $\mathrm{LD}_{50}$ of $\Delta v \operatorname{vg}$ G1-5, $\Delta v \operatorname{vg}$ G1-3, and K96243 in MH cockroaches (Table 1), however, there was a slight but not statistically significant difference in the time to death with these strains. In general, it took longer for $\mathrm{MH}$ cockroaches infected with $\Delta v \operatorname{vrG1-5}$ ' and $\Delta v \operatorname{vrG1-3}$ ' to die relative to K96243 (Figure 2A-C). Thus, these strains appear to have an intermediate virulence phenotype in both $\mathrm{MH}$ cockroaches and in hamsters (Table 1 and Figure 2).

We next examined the relative virulence of the $B$. pseudomallei $\Delta h c p 2$, $\Delta h c p 3, \Delta h c p 4, \Delta h c p 5$, and $\Delta h c p 6$ mutants in $\mathrm{MH}$ cockroaches [9]. These mutants are each deficient in one of the other five T6SSs present in B. pseudomallei and all are virulent in the hamster (Table 1). Figure 3 shows that these strains are also virulent in the MH cockroach and all exhibit a clear dose response. The majority of $\mathrm{MH}$ cockroaches infected with a challenge dose of $10^{1}$ bacteria were dead by day 3 (Figure $3 \mathrm{~A}$ ), but most were dead by day 1 with a challenge dose of $10^{5}$ bacteria (Figure 3E). Interestingly, the $\mathrm{LD}_{50}$ results with these strains are remarkably similar in both $\mathrm{MH}$ cockroaches and hamsters (Table 1).

The virulence of two additional isolates of B. pseudomallei and two isolates of Escherichia coli were also tested in the $\mathrm{MH}$ cockroach. The $\mathrm{LD}_{50} \mathrm{~S}$ of $B$. pseudomallei 1026b and MSHR305 were $<10$ bacteria and the $\mathrm{LD}_{50} \mathrm{~S}$ for E. coli MC4100 and $\mathrm{B} / \mathrm{r}$ were $>10^{5}$ bacteria, the highest dose tested (Table 1). The results suggest that virulence for the $\mathrm{MH}$ cockroach is common among $B$. pseudomallei isolates and that not all gram-negative bacteria are pathogenic for this surrogate host (Table 1).

Taken together, the results demonstrate that $B$. pseudomallei is highly virulent in the $\mathrm{MH}$ cockroach and indicate that this insect might serve as a surrogate host for high throughput virulence screening assays. In addition, the $\mathrm{MH}$ cockroach challenge results are consistent with what is seen in the hamster model of infection and suggest that the primary function of the T6SS-1 is to evade the innate immune system.

\section{The $\mathrm{MH}$ cockroach can serve as a surrogate host for B. mallei and B. thailandensis}

We also evaluated the virulence of $B$. mallei and $B$. thailandensis in the $\mathrm{MH}$ cockroach. The $\mathrm{LD}_{50} \mathrm{~S}$ for $B$. mallei SR1 (Bm) and B. thailandensis DW503 (Bt) were $<10$ bacteria (Table 1 ) and the number and rate of deaths increased as the challenge dose increased from $10^{1}$ to $10^{3}$ bacteria (Figure 4). Interestingly, B. mallei killed the $\mathrm{MH}$ cockroaches at a slower rate than $B$. thailandensis (and B. pseudomallei). It took only 2 days for B. thailandensis to kill $75 \%$ of the $\mathrm{MH}$ cockroaches with a dose of $10^{1}$ bacteria, whereas it took $B$. mallei 5 days (Figure 4A). Similar trends were apparent with challenge doses of $10^{2}$ and $10^{3}$ bacteria (Figure $4 \mathrm{~B}$ and $C$ ). B. mallei does not kill rodents as quickly as $B$. pseudomallei and it is more fastidious than $B$. pseudomallei and B. thailandensis, so it may not be too surprising that it took longer to kill $\mathrm{MH}$ cockroaches [4]. These experiments demonstrate that $B$. mallei and $B$. thailandensis are both virulent in the $\mathrm{MH}$ cockroach and suggest that the $\mathrm{MH}$ cockroach might serve as a surrogate host for these bacterial species.

As mentioned above, B. thailandensis is considered to be avirulent in humans and exhibits a higher $\mathrm{LD}_{50}$ in mammalian models of infection than $B$. mallei and B. pseudomallei. Mammals, unlike $\mathrm{MH}$ cockroaches, possess both an innate and an acquired immune system. The fact that $B$. thailandensis is highly virulent 

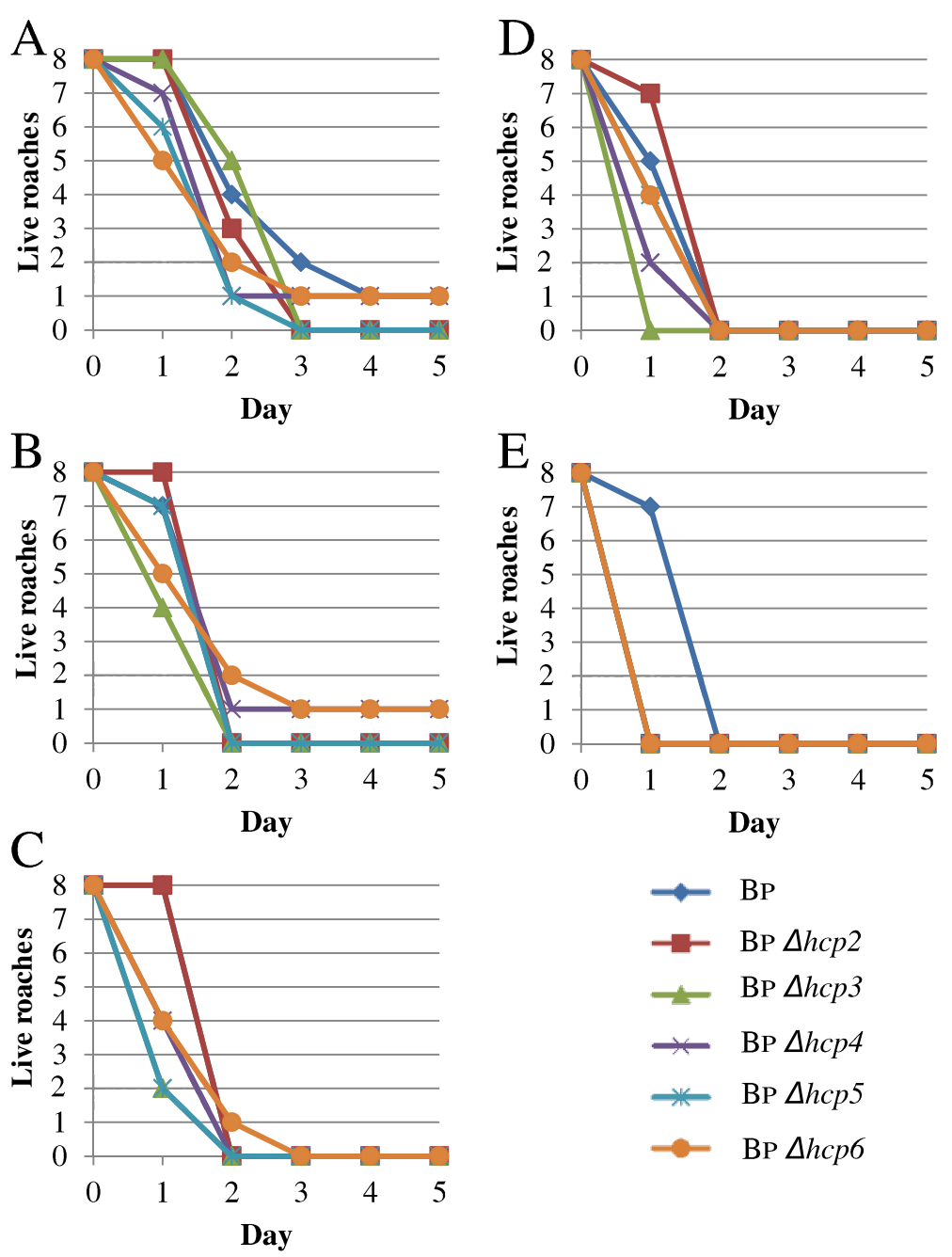

Figure 3 B. pseudomallei T6SS-2, T6SS-3, T6SS-4, T6SS-5, and T6SS-6 mutants are virulent in the MH cockroach. (A) $10^{1} \mathrm{cfu}$. (B) $10^{2} \mathrm{cfu}$. (C) $10^{3} \mathrm{cfu}$. (D) $10^{4} \mathrm{cfu}$. (E) $10^{5} \mathrm{cfu}$. Bp, K96243; Bp $\Delta h c p 2$, DDS0518A; Bp $\Delta h c p 3$, DDS2098A; Bp $\Delta h c p 4, \mathrm{DDS0171A}$; Bp $\Delta h c p 5$, DDS0099A; Bp $\Delta$ hcp6, DDL3105A.

in the $\mathrm{MH}$ cockroach may suggest that the acquired immune system plays an important role in defence against B. thailandensis. B. mallei and B. pseudomallei, on the other hand, may have developed mechanisms to subvert the acquired immune response in mammalian species.

T6SS-1 is a critical virulence determinant for $B$. mallei in the hamster model of infection [25] and for $B$. thailandensis in the C57BL/6 mouse model of infection [27]. We challenged MH cockroaches with B. mallei and B. thailandensis hcp1 mutants and found that they were highly attenuated in this surrogate host (Table 1 and Figure 4). The $\mathrm{LD}_{50} \mathrm{~S}$ for $B$. mallei $\Delta h c p 1$ and $B$. thailandensis $h c p 1^{-}$were $>10^{3}$ bacteria on day 5 , which was at least 100 times higher than their respective parental strains (Table 1 and Figure 4). The B. mallei results were indistinguishable from what was previously described for SR1 and $\Delta h c p 1$ using the hamster model of infection [25]. While the B. thailandensis strains used in this study have not been tested in hamsters, a $B$. thailandensis T6SS1 mutant was recently shown to be avirulent in C57BL/6 mice by the aerosol route of infection [27]. Interestingly,

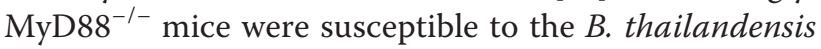
T6SS-1 mutant, which suggests that T6SS-1 plays a role in evading the innate immune response [27]. The fact that B. thailandensis $h c p 1^{-}$was attenuated in an insect host, which lacks an adaptive immune response, further supports the notion that the function of the T6SS-1 is to evade the eukaryotic innate immune system.

\section{B. pseudomallei replicates inside $\mathrm{MH}$ cockroach hemocytes}

Hemocytes are a key component of the $\mathrm{MH}$ cockroach innate immune system and we next examined if $B$. 

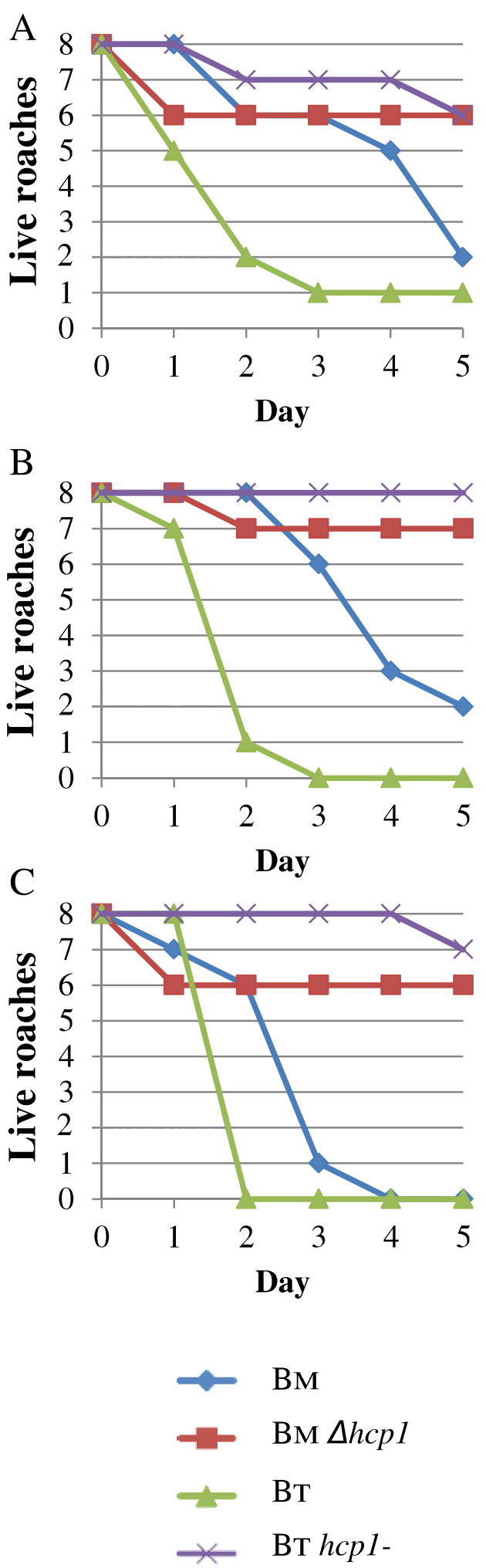

Figure 4 B. mallei and $B$. thailandensis are virulent for the $\mathrm{MH}$ cockroach and their T6SS-1 mutants are attenuated. (A) $10^{1} \mathrm{cfu}$. (B) $10^{2}$ cfu. (C) $10^{3} \mathrm{cfu}$. Bm, SR1; Bm $\Delta$ hcp 1, DDA0742; Bt, DW503; Bt $\Delta h c p 1, \mathrm{DD} \| 0868$. pseudomallei might be exploiting these phagocytic cells to gain an upper hand in the host-pathogen interaction. A group of eight $\mathrm{MH}$ cockroaches were infected with $10^{3}$ B. pseudomallei $\mathrm{K} 96243$ and closely monitored for $48 \mathrm{~h}$. MH cockroaches that appeared weak and lethargic were immediately separated from the others and hemolymph was obtained. The $\mathrm{MH}$ cockroach hemolymph, which contains phagocytic hemocytes, was fixed and stained with DAPI. Figure 5A shows a representative field containing the blue-staining nuclei from multiple hemocytes. As expected, the non-nuclear regions of most hemocytes could not be visualized with this fluorescent DNA stain. Interestingly, each field also contained one or two hemocytes in which the nucleus and the surrounding cytosol could be easily visualized (Figure 5A, white arrows). We speculated that these particular hematocytes might contain cytosolic B. pseudomallei and we stained the hemolymph with a polyclonal antibody that reacts with $B$. pseudomallei. Figure 5B and $5 \mathrm{C}$ show a representative micrograph of a hematocyte engorged with cytosolic B. pseudomallei, suggesting that the bacteria are multiplying to high numbers inside these cells. Free bacteria can also be visualized in the hemolymph outside the hemocyte, but it is unclear if these cells are alive or dead (Figure 5B and 5C). Some infected hemocytes appear to have multiple nuclei and may be multinucleated giant cells (MNGCs) (Figure 5). MNGC have been observed in cases of human melioidosis [28] and are often formed when B.pseudomallei infects murine macrophage-like cell lines in vitro [9]. The formation of $B$. pseudomallei-induced MNGCs in vivo in $\mathrm{MH}$ cockroaches is an exciting finding and indicates that MNGCs can form in non-adherent cells freely flowing within the hemolymph.

Based on these results, we hypothesize that $B$. pseudomallei is able to survive the innate immune system of the $\mathrm{MH}$ cockroach by establishing an intracellular niche within the hemocyte. Infected hemocytes harboring numerous cytosolic bacteria may fuse with uninfected hemocytes to form MNGCs, which may serve as a reservoir for continued bacterial replication and protection from the antimicrobial peptides present in the surrounding hemolymph. The amplification of bacteria within phagocytic hemocytes, and their subsequent release, may eventually overwhelm the $\mathrm{MH}$ cockroach and lead to death.

\section{Conclusions}

Our findings indicate that the Madagascar hissing cockroach can serve as a surrogate host for the analysis of host-pathogen interactions with $B$. pseudomallei, $B$. mallei, and $B$. thailandensis. Using this system, we were able to detect virulence differences between parental strains and T6SS-1 mutants that were consistent with 


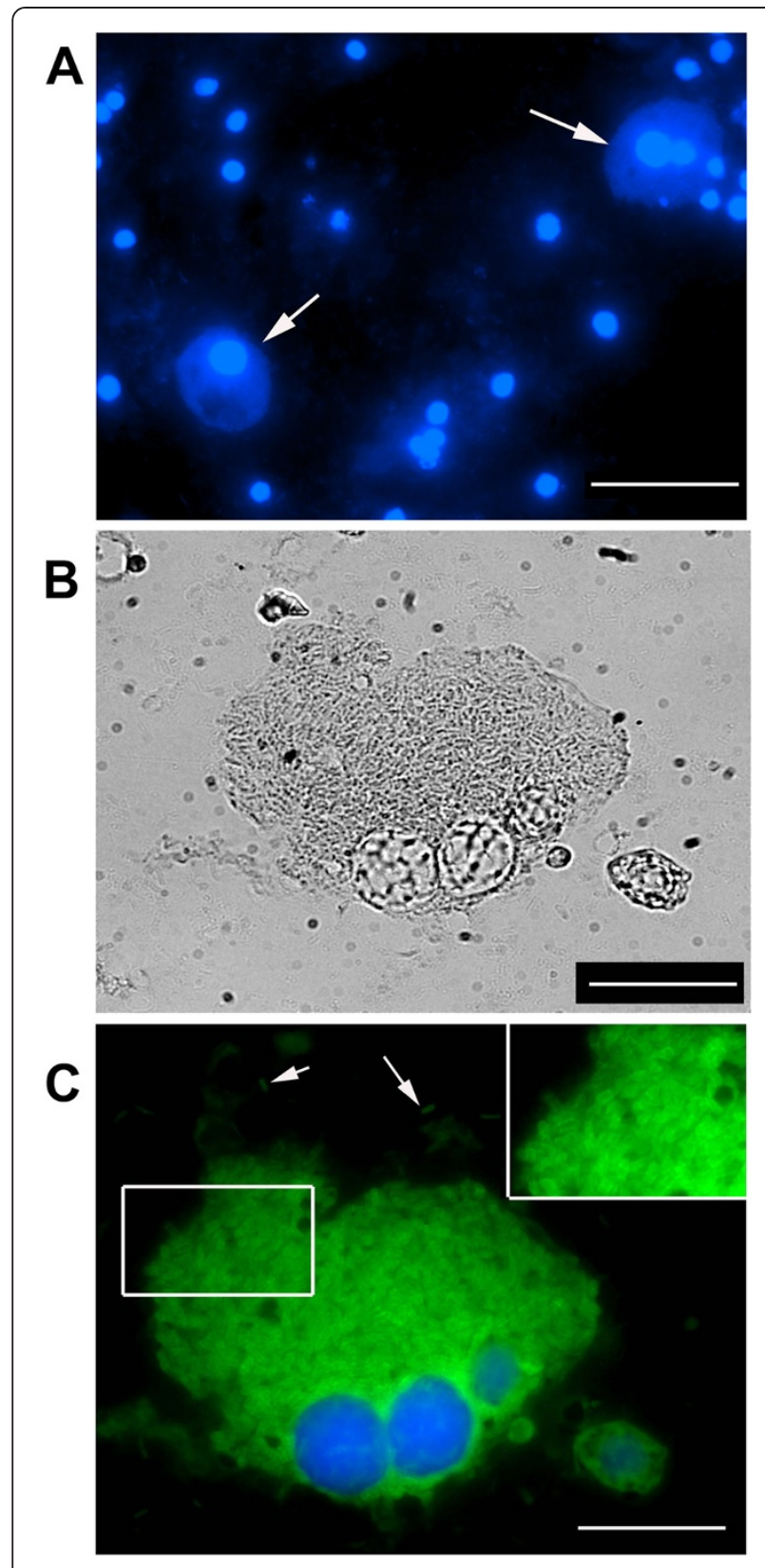

Figure 5 B. pseudomallei multiplies inside $\mathrm{MH}$ cockroach hemocytes. Panel $A$ is a representative micrograph of hemolymph obtained from a MH cockroach infected with B. pseudomallei K96243 and stained with DAPI. The white arrows show hemocytes that harbor intracellular B. pseudomallei. The white scale bar is $100 \mu \mathrm{m}$. Panels $\mathbf{B}$ and $\mathbf{C}$ show a higher magnification of a $\mathbf{B}$. pseudomalleiinfected hemocyte using bright field microscopy (B) and stained with DAPI and a Burkholderia-specific rabbit polyclonal antibody (C) The secondary antibody used, Alexa Fluor 588 goat anti-rabbit lgG, stained $B$. pseudomallei green. The magnified inset in $\mathbf{C}$ shows individual bacilli within the hemocyte cytosol and the white arrows show extracellular bacteria in the hemolymph. The white scale bars in $\mathbf{B}$ and $\mathbf{C}$ are $20 \mu \mathrm{m}$. The results are representative images from eight $\mathrm{MH}$ cockroaches infected with $\sim 10^{3} \mathrm{cfu}$ of $B$. pseudomallei K96243. what was seen in rodent models of infection. $B$. pseudomallei K96243 demonstrated the ability to multiply inside insect hemocytes and form MNGCs, which may be the primary mechanism by which it avoids killing by the $\mathrm{MH}$ cockroach innate immune system. The $\mathrm{MH}$ cockroach will probably be useful for high throughput virulence screening assays with these Burkholderia species as well as other bacterial pathogens.

\section{Methods}

Bacterial strains, plasmids, and growth conditions

The bacterial strains and plasmids used in this study are described in Table 2. E. coli, B. pseudomallei, and B. thailandensis were grown at $37^{\circ} \mathrm{C}$ on Luria-Bertani (Lennox) agar (LB agar) or in LB broth. When appropriate, antibiotics were added at the following concentrations: $15 \mu \mathrm{g}$ of gentamicin $(\mathrm{Gm}), 25 \mu \mathrm{g}$ of streptomycin $(\mathrm{Sm})$, and $25 \mu \mathrm{g}$ of kanamycin $(\mathrm{Km})$ per $\mathrm{ml}$ for $E$. coli and $25 \mu \mathrm{g}$ of polymyxin B (Pm) and $25 \mu \mathrm{g}$ of $\mathrm{Gm}$ per $\mathrm{ml}$ for B. thailandensis. B. mallei was grown at $37^{\circ} \mathrm{C}$ on LB agar with $4 \%$ glycerol or in LB broth with $4 \%$ glycerol. All bacterial strains were grown in broth for $\sim 18 \mathrm{~h}$ with constant agitation at 250 revolutions per minute. Phosphate-buffered saline (PBS) was used to make serial dilutions of saturated bacterial cultures and the number of cfu present in the starting culture were determined by spreading $100 \mu \mathrm{l}$ aliquots onto agar media and incubating for 24-48 h. A $20-\mathrm{mg} / \mathrm{ml}$ stock solution of the chromogenic indicator 5-bromo-4-chloro-3-indolylb-D-galactoside (X-Gal) was prepared in N,N-dimethylformamide, and $40 \mu \mathrm{l}$ was spread onto the surface of plate medium for blue/white screening in E. coli TOP10. All manipulations with $B$. pseudomallei and B. mallei were carried out in class II and class III microbiological safety cabinets located in designated biosafety level 3 (BSL-3) laboratories.

\section{PCR}

The two deoxyribonucleotide primers used for PCR amplification of an internal gene fragment of $B$. thailandensis BTH_II0868 (hcp1) were purchased from Invitrogen (Frederick, MD) and designated II0868-up (5'-AGGGCAA GATTCTCGTCCAG-3') and II0868-dn (5'-TCTCGTACGT GAACGATACG-3'). The PCR product was sized and isolated using agarose gel electrophoresis, cloned using the pCR2.1-TOPO TA Cloning Kit (Invitrogen), and transformed into chemically competent E. coli TOP10. PCR amplification was performed in a final reaction volume of $100 \mu \mathrm{l}$ containing 1X Taq PCR Master Mix (Qiagen), $1 \mu \mathrm{M}$ oligodeoxyribonucleotide primers, and approximately 200 ng of B. thailandensis DW503 genomic DNA. PCR cycling was performed using a PTC-150 MiniCycler with a Hot Bonnet accessory (MJ Research, Inc.) and heated to $97^{\circ} \mathrm{C}$ for $5 \mathrm{~min}$. This was followed by 30 cycles 
Table 2 Strains and plasmids used in this study

\begin{tabular}{|c|c|c|}
\hline Strain or plasmid & Relevant characteristics $^{\mathrm{a}}$ & Source or reference \\
\hline \multicolumn{3}{|l|}{ E. coli } \\
\hline TOP10 & General cloning and blue/white screening & Invitrogen \\
\hline S17-1 & $\begin{array}{l}\text { Mobilizing strain with transfer genes of RP4 integrated } \\
\text { on chromosome; } \mathrm{Sm}^{r}, \mathrm{Pm}^{\mathrm{s}}\end{array}$ & [34] \\
\hline MC4100 & K-12 laboratory strain & [35] \\
\hline$B / r$ & B laboratory strain & [36] \\
\hline \multicolumn{3}{|l|}{ B. pseudomallei } \\
\hline K96243 & $\begin{array}{l}\text { Isolated in Thailand from a diabetic patient with a clinical } \\
\text { history of short incubation, septicemic infection, and rapid progression to death }\end{array}$ & [37] \\
\hline DDS1498A & K96243 derivative harboring a 162-bp in-frame deletion mutation in $h c p 1$ ( $\Delta$ hcp 1) & [9] \\
\hline DDS0518A & K96243 derivative harboring a 303-bp in-frame deletion mutation in $h c p 2(\Delta h c p 2)$ & [9] \\
\hline DDS2098A & K96243 derivative harboring a 186-bp in-frame deletion mutation in $h c p 3(\Delta h c p 3)$ & [9] \\
\hline DDS0171A & K96243 derivative harboring a 321-bp in-frame deletion mutation in $h c p 4(\Delta h c p 4)$ & [9] \\
\hline DDS0099A & K96243 derivative harboring a 192-bp in-frame deletion mutation in hcp5 ( $\Delta$ hcp5) & [9] \\
\hline DDL3105A & K96243 derivative harboring a 216-bp in-frame deletion mutation in $h c p 6(\Delta h c p 6)$ & [9] \\
\hline DDS1503-1A & $\begin{array}{l}\text { K96243 derivative harboring a deletion of the 743-bp Stul fragment at the } 5^{\prime} \text { end of } \\
\text { vgrG1 ( } \Delta \text { vgrG1-5) }\end{array}$ & [9] \\
\hline DDS1503-2A & $\begin{array}{l}\text { K96243 derivative harboring a deletion of the 894-bp Pstl fragment at the } 3^{\prime} \text { end of } \\
\text { vgrG1 ( } \Delta \text { vgrG1-3) }\end{array}$ & [9] \\
\hline $1026 b$ & $\begin{array}{l}\text { Isolated in Thailand from a human case of septicemic melioidosis with skin, soft tissue, } \\
\text { and spleen involvement }\end{array}$ & [30] \\
\hline MSHR305 & Isolated from the brain of a fatal human melioidosis encephalomyelitis case in Australia & {$[38,39]$} \\
\hline \multicolumn{3}{|l|}{ B. mallei } \\
\hline SR1 & ATCC 23344 sucrose-resistant derivative & [40] \\
\hline DDA0742 & $\begin{array}{l}\text { SR1 derivative harboring a deletion of the } 156 \mathrm{bp} \text { Narl-Sful fragment internal } \\
\text { to } h c p 1 ; \Delta h c p 1\end{array}$ & [25] \\
\hline \multicolumn{3}{|l|}{ B. thailandensis } \\
\hline DW503 & E264 derivative; $\Delta$ (amrR-oprA) (Gms) rpsL (Sm') & [41] \\
\hline DDII0868 & DW503::pGSV3-0868; Gmr; hcp1- & This study \\
\hline \multicolumn{3}{|l|}{ Plasmids } \\
\hline PCR2.1-TOPO & 3,931-bp TA vector; pMB1 oriR; $\mathrm{Km}^{\mathrm{r}}$ & Invitrogen \\
\hline pCR2.1-0868 & $\begin{array}{l}\text { pCR2.1-TOPO containing 342-bp PCR product generated with II0868-up } \\
\text { and II0868-dn }\end{array}$ & This study \\
\hline pGSV3 & Mobilizabile $\mathrm{Gm}^{r}$ suicide vector & {$[42]$} \\
\hline pGSV3-0868 & pGSV3 derivative containing EcoRI insert from pCR2.1-0868 & This study \\
\hline
\end{tabular}

${ }^{\mathrm{a}}$ r, resistant; s, susceptible.

of a three-temperature cycling protocol $\left(97^{\circ} \mathrm{C}\right.$ for $30 \mathrm{~s}$, $55^{\circ} \mathrm{C}$ for $30 \mathrm{~s}$, and $72^{\circ} \mathrm{C}$ for $1 \mathrm{~min}$ ) and one cycle at $72^{\circ} \mathrm{C}$ for $10 \mathrm{~min}$.

\section{DNA manipulation and plasmid conjugation}

Restriction enzymes, Antarctic phosphatase, and T4 DNA ligase were purchased from Roche Molecular Biochemicals and were used according to the manufacturer's instructions. DNA fragments used in cloning procedures were excised from agarose gels and purified with a GeneClean III kit (Q - BIOgene). Bacterial genomic DNA was prepared by a previously described protocol [29]. Plasmids were purified from overnight cultures by using Wizard Plus SV Minipreps (Promega). Plasmid pGSV3-0868 (Table 2) was electroporated into E. coli S17-1 $(12.25 \mathrm{kV} / \mathrm{cm})$ and conjugated with $B$. thailandensis for $8 \mathrm{~h}$, as described elsewhere [30]. Pm was used to counterselect E. coli S17-1 (pGSV3-0868).

\section{MH cockroach housing and manipulation}

Madagascar hissing cockroaches, Gromphadorhina laevigata, were purchased from Carolina Biological Supply Company (Burlington, NC) as 1-2 inch nymphs (Figure 1) and were housed in the dark at 
room temperature in a $7.5^{\mathrm{N}} \mathrm{w} \times 11.75 \mathrm{l} \times 5^{\mathrm{\prime}} \mathrm{h}$ mouse cage with a filtered top (Allentown Caging Equipment Co., Inc., Allentown, NJ). The bottom of the cage was lined with cocoa mulch and a thin layer of petroleum jelly was spread around the top portion of the cage to prevent $\mathrm{MH}$ cockroaches from climbing up the sides. Dog food was spread on the bottom of the cage for food and the top of a petri dish was inverted and filled with water for drinking. On occasion, sliced apple wedges were placed in the cage as an additional source of food.

For bacterial infection experiments, 1.5-2 inch juvenile $\mathrm{MH}$ cockroaches were used (Figure 1). We also tested larger $\mathrm{MH}$ cockroaches (> 3 inches) and they displayed the same susceptibility as the juveniles (data not shown). Bacteria were inoculated into the dorsal abdominal section of $\mathrm{MH}$ cockroaches, between the third and the fifth terga (from the posterior), using a $1 \mathrm{ml}$ syringe fitted with a $3 / 8$ inch, 26 -gauge needle (see Figure 1). The syringe was loaded into a Tridak STEPPER series repetitive pipette (Tridak LLC, Torrington, CT) and a $25 \mu \mathrm{l}$ aliquot was injected into $\mathrm{MH}$ cockroaches. A group of eight infected $\mathrm{MH}$ cockroaches were placed in a 16-ounce plastic container with a few pieces of dog food and 1-2 $\mathrm{ml}$ of water. The containers were placed in a $37^{\circ} \mathrm{C}$ incubator and deaths were recorded for 5 days. Food and water levels were checked daily and replenished if needed. The $\mathrm{LD}_{50} \mathrm{~s}$ were calculated 5 days postinfection according to the Reed-Muench method [31].

\section{Extraction and staining of hemolymph from infected $\mathrm{MH}$ cockroaches}

Eight MH cockroaches were infected with $\sim 10^{3} \mathrm{~B}$. pseudomallei K96243 and monitored daily as described above. Hemolymph was extracted from MH cockroaches that were lethargic and on the verge of death. Holding the $\mathrm{MH}$ cockroach with its ventral side up, one hind leg was folded up towards the head to expose the membrane at the base of the leg. The membrane was punctured with a 26-gauge needle and hemolymph was immediately collected using a P200 Gilson PIPETMAN. We used a pipette tip cut with scissors approximately a $1 / 2$ inch from the end to aid in uptake of the viscous hemolyph. The amber-colored hemolymph was transferred to a glass slide, allowed to air dry, and then fixed with methanol. The samples were initially stained with 4', 6-diamidino-2-phenylindole (DAPI) and viewed on a Nikon Eclipse TE2000-S inverted microscope equipped with a Spot-RT digital camera (Image Systems, Columbia, MD). Subsequently, the samples were incubated for $1 \mathrm{~h}$ with a 1:1000 dilution of rabbit polyclonal Burkholderia antiserum [32] and then reacted for $1 \mathrm{~h}$ with a 1:500 dilution of an Alexa Fluor 588 goat anti-rabbit IgG secondary antibody (Molecular Probes) and visualized by fluorescence microscopy.

\section{Abbreviations}

MH: Cockroach; Madagascar: Hissing cockroach; T6SS-1: Ccluster 1 type VI secretion system; LD 50 : 50\% lethal dose; MNGC: Multinucleated giant cell; Cfu: Colony forming units; DAPI: 4', 6-diamidino-2-phenylindole.

\section{Authors' contributions}

NAF conceived use of the MH cockroach as a surrogate host, contributed to the experimental design, and helped draft the manuscript. WJR was involved with the extraction, staining, and fluorescence microscopy of $\mathrm{MH}$ cockroach hemolymph. WA participated in the study design and conducted experiments. DD designed and conducted the experiments and drafted the manuscript. All authors read and approved the final manuscript.

\section{Authors' information}

Opinions, interpretations, conclusions, and recommendations are those of the author and are not necessarily endorsed by the U.S. Army or Department of Homeland Security.

\section{Acknowledgements}

This project received support from DTRA/JSTO-CBD proposal number CBS. MEDBIO.02.10.RD.034 (to D.D.).

\section{Author details}

${ }^{1}$ Center for Genomic Sciences, United States Army Medical Research Institute of Infectious Diseases, Fort Detrick, Frederick, MD 21702, USA. ${ }^{2}$ Bacteriology Division, United States Army Medical Research Institute of Infectious Diseases, 1425 Porter St., Fort Detrick, Frederick, MD (301)

21702-5011, USA. ${ }^{3}$ University of Maryland School of Medicine, Baltimore 21201 (WA), MD, USA.

Received: 18 April 2012 Accepted: 7 June 2012

Published: 22 June 2012

\section{References}

1. Waag DM, DeShazer D: Glanders: new insights into an old disease. In Biological Weapons Defense: Infectious Diseases and Counterbioterrorism. Edited by Lindler LE, Lebeda FJ, Korch GW. Totowa, New Jersey: Humana Press Inc; 2004:209-237.

2. Vietri NJ, DeShazer D: Melioidosis. In Medical Aspects of Biological Warfare. Edited by Dembek ZF. Washington, DC: Department of the Army, Office of The Surgeon General, Borden Institute; 2007:147-166.

3. Brett PJ, DeShazer D, Woods DE: Burkholderia thailandensis sp. nov., description of a Burkholderia pseudomallei-like species. Int I Syst Bacteriol 1998, 48:317-320.

4. Galyov EE, Brett PJ, DeShazer D: Molecular insights into Burkholderia pseudomallei and Burkholderia mallei pathogenesis. Annu Rev Microbiol 2010, 64:495-517.

5. D'Cruze T, Gong L, Treerat P, Ramm G, Boyce JD, Prescott M, Adler B, Devenish RJ: Role for the Burkholderia pseudomallei type three secretion system cluster 1 bpscN gene in virulence. Infect Immun 2011, 79(9):3659-3664.

6. Stevens MP, Haque A, Atkins T, Hill J, Wood MW, Easton A, Nelson M, Underwood-Fowler C, Titball RW, Bancroft GJ, et al: Attenuated virulence and protective efficacy of a Burkholderia pseudomallei bsa type III secretion mutant in murine models of melioidosis. Microbiology 2004, 150(Pt 8):2669-2676.

7. Warawa J, Woods DE: Type III secretion system cluster 3 is required for maximal virulence of Burkholderia pseudomallei in a hamster infection model. FEMS Microbiol Lett 2005, 242:101-108.

8. Stevens MP, Stevens JM, Jeng RL, Taylor LA, Wood MW, Hawes P, Monaghan P, Welch MD, Galyov EE: Identification of a bacterial factor required for actin-based motility of Burkholderia pseudomallei. Mol Microbiol 2005, 56:40-53.

9. Burtnick MN, Brett PJ, Harding SV, Ngugi SA, Ribot WJ, Chantratita N, Scorpio A, Milne TS, Dean RE, Fritz DL, et al: The cluster 1 type VI secretion system is a major virulence determinant in Burkholderia pseudomallei. Infect Immun 2011, 79(4):1512-1525. 
10. Shalom G, Shaw JG, Thomas MS: In vivo expression technology identifies a type VI secretion system locus in Burkholderia pseudomallei that is induced upon invasion of macrophages. Microbiology 2007, 153:2689-2699.

11. Burtnick MN, DeShazer D, Nair V, Gherardini FC, Brett PJ: Burkholderia mallei cluster 1 type $\mathrm{VI}$ secretion mutants exhibit growth and actin polymerization defects in RAW 264.7 murine macrophages. Infect Immun 2010, 78(1):88-99.

12. French CT, Toesca IJ, Wu TH, Teslaa T, Beaty SM, Wong W, Liu M, Schröder I, Chiou PY, Teitell MA, et al: Dissection of the Burkholderia intracellular life cycle using a photothermal nanoblade. Proc Natl Acad Sci USA 2011, 108 (29):12095-12100.

13. Dorer MS, Isberg RR: Non-vertebrate hosts in the analysis of hostpathogen interactions. Microbes Infect 2006, 8:1637-1646.

14. Steinert M, Leippe M, Roeder T: Surrogate hosts: protozoa and invertebrates as models for studying pathogen-host interactions. Int $\mathrm{J}$ Med Microbiol 2003, 293:321-332.

15. Schell MA, Lipscomb L, DeShazer D: Comparative genomics and an insect model rapidly identify novel virulence genes of Burkholderia mallei. J Bacteriol 2008, 190(7):2306-2313.

16. Wand ME, Müller CM, Titball RW, Michell SL: Macrophage and Galleria mellonella infection models reflect the virulence of naturally occurring isolates of B. pseudomallei, B. thailandensis and B. oklahomensis. BMC Microbiol 2011, 11:11.

17. Hasselbring BM, Patel MK, Schell MA: Dictyostelium discoideum as a model system for identification of Burkholderia pseudomallei virulence factors. Infect Immun 2011, 79(5):2079-2088.

18. Gan YH, Chua KL, Chua HH, Liu B, Hii CS, Chong HL, Tan P: Characterization of Burkholderia pseudomallei infection and identification of novel virulence factors using a Caenorhabditis elegans host system. Mol Microbiol 2002, 44(5):1185-1197.

19. Lee SH, Ooi SK, Mahadi NM, Tan MW, Nathan S: Complete killing of Caenorhabditis elegans by Burkholderia pseudomallei is dependent on prolonged direct association with the viable pathogen. PLoS One 2011, 6(3):e16707.

20. O'Quinn AL, Wiegand EM, Jeddeloh JA: Burkholderia pseudomallei kills the nematode Caenorhabditis elegans using an endotoxin-mediated paralysis. Cell Microbiol 2001, 3(6):381-393.

21. Lee $Y H$, Chen $Y$, Ouyang $X$, Gan $Y H$ : Identification of tomato plant as a novel host model for Burkholderia pseudomallei. BMC Microbiol 2010, 10(28).

22. Kavanagh $K$, Reeves EP: Insect and mammalian innate immune responses are much alike. Microbe 2007, 2(12):596-599.

23. Sifri CD, Ausubel FM: Use of simple non-vertebrate hosts to model mammalian pathogenesis. In Cellular Microbiology. Secondth edition. Edited by Cossart P, Boquet P, Normark S, Rappuoli R. Washington, D.C: ASM Press; 2004:543-563

24. Lavine MD, Strand MR: Insect hemocytes and their role in immunity. Insect Biochem Mol Biol 2002, 32(10):1295-1309.

25. Schell MA, Ulrich RL, Ribot WJ, Brueggemann EE, Hines HB, Chen D, Lipscomb L, Kim HS, Mrázek J, Nierman WC, et al: Type VI secretion is a major virulence determinant in Burkholderia mallei. Mol Microbiol 2007, 64(6):1466-1485

26. Pukatzki S, McAuley SB, Miyata ST: The type VI secretion system: translocation of effectors and effector-domains. Curr Opin Microbiol 2009, 12(1):11-17.

27. Schwarz S, West TE, Boyer F, Chiang WC, Carl MA, Hood RD, Rohmer L, Tolker-Nielsen T, Skerrett SJ, Mougous JD: Burkholderia type VI secretion systems have distinct roles in eukaryotic and bacterial cell interactions. PLOS Pathog 2010, 6(8):e1001068.

28. Wong KT, Puthucheary SD, Vadivelu J: The histopathology of human melioidosis. Histopathology 1995, 26(1):51-55.

29. Wilson K: Preparation of genomic DNA from bacteria. In Current Protocols in Molecular Biology. Edited by Ausubel FM, Brent R, Kingston RE, Moore DD, Seidman JG, Smith JA, Struhl K. New York: John Wiley \& Sons; 1987:2.4.1-2.4.5.

30. DeShazer D, Brett PJ, Carlyon R, Woods DE: Mutagenesis of Burkholderia pseudomallei with Tn5-OT182: Isolation of motility mutants and molecular characterization of the flagellin structural gene. J Bacteriol 1997, 179:2116-2125.

31. Reed $\amalg$, Muench $H$ : A simple method of estimating fifty per cent endpoints. Am J Hyg 1938, 27(3):493-497.
32. Burtnick MN, Brett PJ, Nair V, Warawa JM, Woods DE, Gherardini FC: Burkholderia pseudomallei type III secretion system mutants exhibit delayed vacuolar escape phenotypes in RAW 264.7 murine macrophages. Infect Immun 2008, 76(7):2991-3000.

33. Brett PJ, DeShazer D, Woods DE: Characterization of Burkholderia pseudomallei and Burkholderia pseudomallei-like strains. Epidemiol Infect 1997, 118(2):137-148.

34. Simon $R$, Priefer $U$, Puhler A: A broad host range mobilization system for in vivo genetic engineering: tranposon mutagenesis in gram negative bacteria. Bio/Technology 1983, 1:784-791.

35. Ferenci T, Zhou Z, Betteridge T, Ren Y, Liu Y, Feng L, Reeves PR, Wang L: Genomic sequencing reveals regulatory mutations and recombinational events in the widely used MC4100 lineage of Escherichia coli K-12. J Bacteriol 2009, 191(12):4025-4029.

36. Witkin EM: Inherited differences in sensitivity to radiation in Escherichia coli. Proc Natl Acad Sci U S A 1946, 32(3):59-68.

37. Holden MT, Titball RW, Peacock SJ, Cerdeno-Tarraga AM, Atkins T, Crossman LC, Pitt T, Churcher C, Mungall K, Bentley SD, et al: Genomic plasticity of the causative agent of melioidosis, Burkholderia pseudomallei. Proc Natl Acad Sci 2004, 101:14240-14245.

38. Currie BJ, Fisher DA, Howard DM, Burrow JN, Lo D, Selva-Nayagam S, Anstey NM, Huffam SE, Snelling PL, Marks PJ, et al: Endemic melioidosis in tropical northern Australia: a 10-year prospective study and review of the literature. Clin Infect Dis 2000, 31:981-986.

39. Tuanyok A, Auerbach RK, Brettin TS, Bruce DC, Munk AC, Detter JC, Pearson T, Hornstra H, Sermswan RW, Wuthiekanun V, et al: A horizontal gene transfer event defines two distinct groups within Burkholderia pseudomallei that have dissimilar geographic distributions. J Bacteriol 2007, 189(24):9044-9049.

40. Ulrich RL, Amemiya K, Waag DM, Roy CJ, Deshazer D: Aerogenic vaccination with a Burkholderia mallei auxotroph protects against aerosol-initiated glanders in mice. Vaccine 2005, 23:1986-1992.

41. Burtnick MN, Bolton AJ, Brett PJ, Watanabe D, Woods DE: Identification of the acid phosphatase $($ acpA) gene homologues in pathogenic and nonpathogenic Burkholderia spp. facilitates TnphoA mutagenesis. Microbiology 2001, 147:111-120.

42. DeShazer D, Waag DM, Fritz DL, Woods DE: Identification of a Burkholderia mallei polysaccharide gene cluster by subtractive hybridization and demonstration that the encoded capsule is an essential virulence determinant. Microb Pathogen 2001, 30:253-269.

doi:10.1186/1471-2180-12-117

Cite this article as: Fisher et al:: The Madagascar hissing cockroach as a novel surrogate host for Burkholderia pseudomallei, B. mallei and $B$. thailandensis. BMC Microbiology 2012 12:117.

\section{Submit your next manuscript to BioMed Central and take full advantage of:}

- Convenient online submission

- Thorough peer review

- No space constraints or color figure charges

- Immediate publication on acceptance

- Inclusion in PubMed, CAS, Scopus and Google Scholar

- Research which is freely available for redistribution 